\title{
Modelling the BRICS Exchange Rates Using the Vector Autoregressive (VAR) Model
}

\author{
Lebotsa Daniel Metsileng, Ntebogang Dinah Moroke, Johannes Tshepiso Tsoku \\ North West University, Corner Dr Albert Lithuli, Mmabatho, South Africa \\ Dan.metsileng@gmail.com, Ntebo.moroke@nwu.ac.za, Johannes.tsoku@nwu.ac.za
}

\begin{abstract}
The paper modelled the BRICS exchange rates using the Vector Autoregressive (VAR) model. Monthly time series data ranging from January 2008 to January 2018 was used. All the analysis was computed using the $\mathrm{R}$ programming software. The study aimed to determine a suitable VAR model in modelling the BRICS exchange rates and determine the linear dependency between the financial markets (in particular BRICS exchange rates). Optimal lag length of one (1) was selected using the SIC. The VAR model with lag length one was fitted and the parameters were estimated. The results revealed that there is a unidirectional relationship amongst the BRICS exchange rates. The VAR (1) model did not satisfy all the diagnostic tests, therefore forecasting future values of the BRICS exchange rates could not be computed. Recommendations for different approaches were formulated.
\end{abstract}

Keywords: VAR model, BRICS Exchange rates, Volatility, linear dependency and forecasting

\section{Introduction}

The volatility and interdependence in the BRICS exchange rates play a key role in inter-trade relations. According to Wang and Zivot (2006) interdependence is referred to as "observed behavioral pattern on a variable due to the influence of another variable". The Vector Autoregressive (VAR) model is used to model the behavioral pattern. The VAR models are basically useful for examining the dynamic behavior and interdependency by modelling the conditional mean of the financial time series data. The VAR model is effective in modeling the mean or the first order moment of the series (Lama et al., 2016). It creates a better understanding of the series, modelling and forecasting volatility. VAR models assume a constant one-period forecast variances. The paper hopes to build on previous studies conducted to look into the performance of VAR, models on the time-varying integrated data specifically BRICS exchange rates. The VAR model is chosen due to its ability to deal with data containing heteroskedastic problems as it is a problem contained in exchange rates. The buying power of the BRICS countries is dependent on the set exchange rates and intergovernment trade is also influenced by the exchange rates. BRICS have a set Memorandum of Understanding (MOU) governing their market efficiencies. In the main, exchange rates data are volatile in nature and therefore the variance and covariance ought to be included in modelling any volatile data.

The exchange rates in foreign economies are regarded as the most liquid of all the asset market. These sectors play a major role in all trades involving the cross-border trading, more specifically in the BRICS economies. It is therefore important that there is cooperation and MOUs among inter-trading countries signed to regulate trade. The signed MOUs allow for interdependence among financial markets and it brings about possible gains of two or more interrelated countries. Losses may be contained by taking into account time-varying variance and covariance's. MOUs therefore create a clear understanding and linkages between different economies. Exchange rates increase the will for the BRICS countries to work together to formulate and implement relevant policies that helps in governing trade. The paper investigates and reviews the characteristics of the time-series models that shall be considered. The paper also wishes to determine an appropriate VAR (p) model and estimate the linear dependency between the financial markets (in particular BRICS exchange rates). The rest of the paper is arranged as follows: In Part 2, the literature review is presented; Part 3 gives an outlines of the methodology. In Part 4, results and discussions are presented. Part 5 provides the conclusion of the paper.

\section{Literature Review}

The VAR processes are well known in economics and other sciences since they are flexible and simple models for multivariate time series data. Sims (1980) advocated "for VAR models as alternatives since he questioned the way classical simultaneous equations models were specified and identified". VAR model is a generalization or natural expansion of the univariate autoregressive (AR) model to dynamic multivariate time 
series. The VAR models provide for interesting features that assist in analyzing dynamics within the time series (Adenomon et al., 2013). McMillin (1991) and Lu (2001) are of the view that the model can be used to determine the relationship between the lagged values and the current values of all variable in the system. The VAR model has turned out to be particularly helpful for describing the dynamic conduct of financial and economic time series and for predicting future values. It regularly gives superior forecasts than those from univariate time series models and elaborate theory-based simultaneous equations models.

The causal impacts that follow from the unexpected shocks or innovations to specified variables on the variables in the model are summarized. These causal impacts are normally compressed with impulse response functions and forecast error variance decomposition. As of late, because of its flexibility, VAR model is every now and again utilized for financial and economic data modelling. Furthermore, they have been utilized in many empirical studies of a different discipline. VAR model was utilized to study different variable by different authors including amongst other but not limited to: Bessler (1984); Estenson (1992); Backus (1986); Ono (2011); and Enders and Sandler (1993). Freeman et al. (1989) on the other hand drew a comparison between the VAR model and Structural equation (SEQ) to study politics. Bagliano and Favero (1998) used a VAR model to measure monetary policy as an evaluation. In fact, the empirical literature of the VAR process is numerous. Athanasopoulos et al. (2011) conducted a study in which a joint determination of the lag-length, the dimension of the cointegrating space and the rank of the matrix of short-run parameters of VAR model using model selection criteria.

Monte Carlo simulations were used to measure the improvements in the accuracy of the forecasts. The study applied two empirical of inflation of Brazil and macroeconomic aggregates growth rates of U.S. respectively and the results showed the usefulness of the model-selection strategy proposed in the study. VAR model was utilized to examine the dynamic relationship between the Nigerian rainfall and temperature time series data. The data used was of the Meteorological station covering periods January 1981 to December 2010. The VAR model was further interpreted using the impulse response function and the forecast error variance decomposition. The lag eight for the VAR model was selected by Akaike Information Criterion (AIC) and Hannan-Quinn Information Criterion (HQ). The results showed that modelling the Nigerian rainfall and temperature together will improve the rainfall predictions and temperature respectively (Adenomon et al., 2013). VAR model has had numerous successes in the modelling and forecasting of time series data. Eklund (2007) considered modelling and forecasting Icelandic business cycles. The study used the VAR model to model the general business cycle. The method of selecting monthly variables, coincident and leading, that mimic the cyclical behavior of the quarterly Gross Domestic Product (GDP) is described.

Using the estimated VAR model bootstrap forecasting procedure was applied, point and interval forecasts of the composite coincident were estimated. The findings revealed that there is a positively significant difference response of the oil price indicators to Russia, India and China. The results further revealed a significant asymmetric effect of oil shocks on Indian returns. The association among ISE 100 Index and four macroeconomic variables were examined by Baş̧̧ and Karaca (2012) using the VAR model. Those microeconomic variables are Exchange, Gold, Import and Export. A total of 190 observations were used for a period ranging from January 1996 to October 2011. The one standard deviation shock for each series and their response were given after determining the optimal lag order. The results from the variance decomposition revealed that $31 \%$ of the exchange was explained by the share indices. Similarly, the study by Chamalwa and Bakari (2016) used VAR cointegration and Vector Error Correction Model (VECM) approach to investigate the association between economic growth (GDP), money supply and credit to the private sector for the period 1981 to 2012 .

The findings of the study indicated that all the three variables are stationary after the first differencing. The VAR (1) was selected as the optimum length. The three variables are cointegrated with at most one cointegrating equation. The findings of the study further revealed that there is a b-bidirectional causality running between the three variables. The VECM model found a long run relationship amongst the three (Chamalwa and Bakari, 2016). Enisan and Olufisayo (2009) explored "the long run and casual relationship between stock market performance and economic growth from seven sub-Saharan Africa. The study reported a bidirectional relationship between the development of stock markets and economic growth for Cote D'Ivoire, Kenya, Morocco and Zimbabwe." 
The stock market indexes of South Africa (SA), Indian and the USA was explored by Mohanasundaram and Karthikeyan (2015) to see if there is any association and existence of short-run and long-run relationships between them. Monthly data of stock indexes of JALSH (S.A), NIFTY (India) and NASDAQ (USA) was used covering the period of April 2004 to March 2014. The lag length of order one was selected by Final Prediction Error criterion (FPE), the AIC, the HQ and the Schwarz Information Criterion (SIC). According to the VAR model the results obtained shows that the USA and the SA stock markets are estimated by their own past lags. Ijumba (2013) studied the multivariate analysis of the BRICS financial markets using the BRICS weekly returns ranging from the first month of 2000 to last month of 2012. The VAR model was used to determine the linear dependency between the BRICS markets. The study fitted the VAR model with a lag length of order one selected by AIC, HQ and SIC. The VAR model revealed that there is one directional dependency of the two markets (India and China) on the Brazil market. However, the study did not forecast the BRICS markets since the VAR (1) model failed to satisfy all the diagnostic tests features.

\section{Methodology}

The data used cover the scope before the inception of BRICS ranging from January 2008 to January 2018 and it has 121 observations. The paper employed the monthly exchange rates of the five BRICS countries. The data involves currency exchange rates monthly average. The data used in this paper is a national currency of each of the five countries per US Dollar. It was obtained from the Organization for Economic Cooperation and Development (OECD) website. The BRICS countries are also known as emerging economies. Data analyses in this paper are carried out using R 3.4.4 programming language. Most of the time series used in modelling are non-stationary in nature. By non-stationary, the mean, variance, and autocovariance may depend on time t. A time series is said to be stationary if its mean, variance, and autocovariance are independent of time. In BoxJenkins setting, if the mean of the series is less than its corresponding standard deviation, it is representable as:

$X_{t}=\sum_{j=1}^{p} \phi_{j} X_{t-j}+\varepsilon_{t}+\sum_{k=1}^{q} \theta_{k} \varepsilon_{t-k}$,

where $\phi_{j}: \mathrm{j}=1,2,3, \ldots . \mathrm{p}$ are the AR parameters of order $\mathrm{p}$, and $\theta_{k}: \mathrm{k}=1,2,3, \ldots \mathrm{q}$ are the moving average parameters of order q. Formal tests for non-stationary have now become a standard starting point in applied time series analysis. Several test statistics have been proposed to test the need for differencing the series before modeling. Notable among these are due to Dickey and Fuller (1979), Phillips and Perron (1988), and Hall (1989). The unit root test procedures reviewed in this paper are the Augmented Dickey-Fuller (ADF) test and Phillips-Perron (PP) test. The computed ADF and PP test statistic are given by the following equations respectively:

$\hat{\tau}_{a d f}=\frac{\widehat{\phi}_{1}-1}{\operatorname{Se}\left(\widehat{\phi}_{1}-1\right)^{\prime}}$

$\hat{\tau}_{\mathrm{pp}}=\left(\frac{\mathrm{t}_{\phi_{1}-1}}{\xi}\right) \Gamma_{0}^{\frac{1}{2}}-\frac{\mathrm{N}}{2}\left(\frac{\xi^{2}-\Gamma_{0}}{\xi \hat{\sigma}}\right) S_{\mathrm{e}}\left(\phi_{1}-1\right)$,

where $t_{\phi_{1}-1}$ is the t-statistic of $\phi_{1}-1, \mathrm{~S}_{\mathrm{e}}\left(\phi_{1}-1\right)$ is the standard error of $\phi_{1}-1$, and $\widehat{\sigma}$ is the standard error of the test regression. The asymptotic distributions of the PP test statistics are the same as those of the ADF test statistics. The null hypothesis of a unit root is rejected if the $\hat{\tau}(\mathrm{tau}) \mathrm{p}$-values are less than $5 \%$ significance value.

The Vector Auto Regression Model: This section discusses both the univariate and multivariate VAR models. Multivariate time series use models such as VAR for their ease of utilization nature. The model can also be used as a tool to describe the behaviour of time series and predicting its future occurrences. The model is however effective in describing the different behaviour of the time series and their related forecasts. It gives better forecasts to those from univariate time series models. Zhang et al., (2016) highlighted that "the forecasts derived from VAR models are flexible and can be made conditional on the potential future paths of specified variables in the model". VAR model was introduced by Sims (1980) and are used to capture the dynamic behaviour and multivariate time series interdependency. It is considered as a generalization of 
univariate AR models or a combination between the two or more models and the univariate time series models. Each variable in a VAR is explained by its own lagged values and the lagged values of all the other variables in the equation. The basic VAR (p) model is: given by:

$Y_{t}=G+E_{1} Y_{t-1}+E_{2} Y_{t-2}+\cdots+E_{p} Y_{k-p}+\varepsilon_{t}$

where, $\mathrm{G}$ is $\mathrm{n} \times 1$ vector of intercepts, $\mathrm{E}_{\mathrm{I}}$ is $k \times k$ matrices of parameters where $i=1,2, \ldots, p$ and $\varepsilon_{\mathrm{t}} \sim$ iid, $\mathrm{N}(0, \mathrm{~S})$. The number of parameters to be estimated in the VAR model is $k(1+k p)$ which increases with the number of variables (k) and number of lags (p). The inclusion criterion of the lags (p) in the equations is done using a test of system reduction and the AIC is used to determine the lag length of VAR model. The following criterions are also used: HQ and SIC. The AIC, HQ and SIC and they are represented using the following equation respectively:

$\operatorname{AIC}(p)=\ln |\bar{\Sigma}(p)|+\frac{2}{T} p^{2}$
$\operatorname{HQ}(p)=\ln |\bar{\Sigma}(p)|+\frac{2 \ln \ln T}{T} p^{2}$
$\operatorname{SIC}(p)=\ln |\bar{\Sigma}(p)|+\frac{\ln T}{T} p^{2}$

where $\mathrm{T}$ is the sample size and $\bar{\Sigma}(\mathrm{p})=\mathrm{T}^{-1} \sum_{\mathrm{t}-1}^{\mathrm{T}} \hat{\mu}_{\mathrm{t}} \hat{\mu}_{\mathrm{t}}^{\prime}$. According to Liitkepohl (1991), the AIC criterion asymptotically is said to be overestimating the positive probability of the lag order, while the HQ and BIC criterions do not overestimate. Therefore, the selection is based on the lowest value of the minimum value of the three criterions.

Model Parameter Estimation: The VAR (p) coefficients can be estimated efficiently using either the Maximum Likelihood Estimation (MLE) or the Ordinary Least Squares (OLS) methods. Tsay (2005) confirms that the OLS or the MLE methods are asymptotically similar. This study uses the MLE method to draw an approximation of the coefficients of VAR (p). The matrix process of the VAR model can be presented as:

$\mathrm{R}=\mathrm{DW}+\xi$

where

$\mathrm{R}=\left(\mathrm{r}_{1} \ldots \ldots \ldots \mathrm{r}_{\mathrm{Z}}\right)^{\prime}$

$\mathrm{D}=\left(\mathrm{c} . \mathrm{G}_{1} \ldots \ldots \ldots \mathrm{G}_{\mathrm{p}}\right)^{\prime}$

$\mathrm{W}_{\mathrm{t}}=\left(1, \mathrm{r}_{\mathrm{t}} \ldots \ldots \ldots \mathrm{r}_{\mathrm{t}-\mathrm{p}+1}\right)$

$\mathrm{W}=\left(\mathrm{W}_{0} \ldots \ldots \ldots \mathrm{W}_{\mathrm{Z}-1}\right)^{\prime}$

$\xi=\left(\mu_{1} \ldots \ldots \ldots \mu_{\mathrm{Z}}\right)^{\prime}$

$\mathrm{R}, \mathrm{D}, \mathrm{W}$ and $\xi$ are $(M \times \mathrm{Z}),(\mathrm{M} \times(\mathrm{Mp}+1)),((\mathrm{Mp}+1) \times \mathrm{Z})$ and $(\mathrm{M} \times \mathrm{Z})$ matrices respectively. The MLE of the $\operatorname{VAR}(\mathrm{p})$ model is given as:

$\mathrm{r}=\operatorname{vec}(\mathrm{R})$

$\mathrm{d}=\operatorname{vec}\left(\mathrm{D}^{\prime}\right)$

$\mu=\operatorname{vec}(\xi)$

$\mathrm{R}^{*}=\left(\mathrm{r}_{1-\mu} \ldots \ldots \ldots \mathrm{r}_{\mathrm{Z}-\mu}\right)$

$\mathrm{X}=\left(\mathrm{R}_{0}^{*}, \ldots \ldots \ldots, \mathrm{R}_{\mathrm{Z}-1}^{*}\right)$

$\alpha=\left(G_{1} \ldots \ldots \ldots G_{p}\right)$

where $r, d, \mu$ and $\alpha$ are $(M Z \times 1),\left(\left(M^{2} p+M\right) \times 1\right),(M Z \times 1)$, and $\left(M^{2} p \times 1\right)$ vectors respectively. $R^{*}$ and $X$ are $(\mathrm{M} \times \mathrm{Z})$ and $(\mathrm{Mp} \times \mathrm{Z})$ matrices. The probability density function of $\mu$ is presented as follows:

$\mathrm{f}_{\mu}(\mu)=\frac{1}{(2 \pi)^{\frac{\mathrm{MZ}}{2}}}\left|\sum_{\mu}\right|^{-\frac{1}{2}} \exp \left(-\frac{1}{2} \mu^{\prime} \sum_{\mu} \mu\right)$

where 
$\mu=r-\mu^{*}-\left(X^{\prime} \otimes I_{M}\right) \alpha$

such that

$\mu^{*}=\left(\mu^{\prime}, \ldots, \mu^{\prime}\right)$

Equation (23) is obtained from equation (21)

$\begin{aligned} \mathrm{f}_{\mathrm{r}}(\mathrm{r})= & \left|\frac{\partial \mu}{\partial \mathrm{r}^{\prime}}\right| \mathrm{f}_{\mu}(\mu) \\ & =\frac{1}{(2 \pi)^{\frac{\mathrm{MZ}}{2}}}\left|\mathrm{I}_{\mathrm{Z}} \otimes \sum_{\mathrm{u}}\right|^{-\frac{1}{2}} \exp \left(-\frac{1}{2}\left(\mathrm{r}-\mu^{*}-\left(\mathrm{X}^{\prime} \otimes \mathrm{I}_{\mathrm{M}}\right) \alpha\right)^{\prime}\left(\mathrm{I}_{\mathrm{Z}} \otimes \sum_{\mathrm{u}}^{-1}\right)\left(\mathrm{r}-\mu^{*}-\left(\mathrm{I}_{\mathrm{M}} \otimes \mathrm{X}^{\prime}\right) \alpha\right)^{\prime}\right.\end{aligned}$

Therefore, the likelihood function

$$
\begin{aligned}
\log L\left(\mu, \alpha, \sum_{\mathrm{u}}\right)= & -\frac{\mathrm{MZ}}{2} \log (2 \pi)-\frac{\mathrm{Z}}{2}\left(\sum_{\mathrm{u}}\right)-\frac{1}{2}\left(\mathrm{r}-\mu^{*}-\left(\mathrm{X}^{\prime} \otimes \mathrm{I}_{\mathrm{M}}\right) \alpha\right)^{\prime}\left(\left(\mathrm{I}_{\mathrm{Z}} \otimes \sum_{\mathrm{u}}^{-1}\right) \times\left(\left(\mathrm{I}_{\mathrm{Z}} \otimes \sum_{\mathrm{u}}^{-1}\right)\right.\right. \\
= & -\frac{\mathrm{MZ}}{2} \log (2 \pi)-\frac{\mathrm{Z}}{2} \log \mid \sum_{\mathrm{u}} \mathrm{l}-\frac{1}{2} \sum_{\mathrm{t}=1}^{\mathrm{Z}}\left(\left(\mathrm{r}_{\mathrm{t}}-\mu\right)-\sum_{\mathrm{i}=1}^{\mathrm{P}} \mathrm{G}_{\mathrm{i}}\left(\mathrm{r}_{\mathrm{t}-\mathrm{i}}-\mu\right)\right)^{\prime} \sum_{\mu} \times\left(\left(\mathrm{r}_{\mathrm{t}}-\mu\right)\right. \\
& \left.\quad-\sum_{\mathrm{i}=1}^{\mathrm{P}} \mathrm{G}_{\mathrm{i}}\left(\mathrm{r}_{\mathrm{t}-\mathrm{i}}-\mu\right)\right) \\
= & -\frac{\mathrm{MZ}}{2} \log (2 \pi)-\frac{\mathrm{Z}}{2} \log \mid \sum_{\mathrm{u}} \mathrm{l}-\frac{1}{2} \sum_{\mathrm{t}}\left(\mathrm{r}_{\mathrm{t}}-\sum_{\mathrm{i}} \mathrm{G}_{\mathrm{i}} \mathrm{r}_{\mathrm{t}-\mathrm{i}}\right)^{\prime} \sum_{\mathrm{u}}^{-1}\left(\mathrm{r}_{\mathrm{t}}-\sum_{\mathrm{i}} \mathrm{G}_{\mathrm{i}} \mathrm{r}_{\mathrm{t}-\mathrm{i}}\right) \\
& \quad+\mu^{\prime}\left(\mathrm{I}_{\mathrm{M}}-\sum_{\mathrm{i}}^{\mathrm{i}} \mathrm{G}_{\mathrm{i}}\right)^{\prime} \sum_{\mathrm{u}}^{-1} \sum_{\mathrm{t}}\left(\mathrm{r}_{\mathrm{t}}-\sum_{\mathrm{i}} \mathrm{G}_{\mathrm{i}} \mathrm{r}_{\mathrm{t}-\mathrm{i}}\right)-\frac{\mathrm{Z}}{2} \mu^{\prime}\left(\mathrm{I}_{\mathrm{M}}-\sum_{\mathrm{i}} \mathrm{G}_{\mathrm{i}}\right)^{\prime} \sum_{\mathrm{u}}^{-1}\left(\mathrm{I}_{\mathrm{M}}-\sum_{\mathrm{i}} \mathrm{G}_{\mathrm{i}}\right) \mu \\
=- & -\frac{\mathrm{MZ}}{2} \log (2 \pi)-\frac{\mathrm{Z}^{2}}{2} \log \mid \sum_{\mathrm{u}} \mathrm{l}-\frac{1}{2} \operatorname{tr}\left[\left(\mathrm{R}^{*}-\mathrm{GX}^{\prime} \sum_{\mathrm{u}}^{-1}\left(\mathrm{R}^{*}-\mathrm{GX}\right)\right]\right.
\end{aligned}
$$

To find the MLE of $\mu, \alpha, \sum_{\mu}$, first order of the $\partial \mathrm{f}(\mathrm{x} ; \mathrm{r}) \partial \mathrm{x}$ of the likelihood function is considered:

$$
\begin{aligned}
\frac{\partial \log \mathrm{L}}{\partial \mu} & =\left(\mathrm{I}_{\mathrm{M}}-\sum_{\mathrm{i}} \mathrm{G}_{\mathrm{i}}\right) \sum_{\mathrm{u}}^{-1} \sum_{\mathrm{t}}\left(\mathrm{r}_{\mathrm{t}}-\sum_{\mathrm{i}} \mathrm{G}_{\mathrm{i}} \mathrm{r}_{\mathrm{t}-\mathrm{i}}\right)-\left(\mathrm{I}_{\mathrm{M}}-\sum_{\mathrm{i}} \mathrm{G}_{\mathrm{i}}\right)^{\prime} \sum_{\mathrm{u}}^{-1}\left(\mathrm{I}_{\mathrm{M}}-\sum_{\mathrm{i}} \mathrm{G}_{\mathrm{i}}\right) \mu \\
& =\left(\mathrm{I}_{\mathrm{M}}-\mathrm{G}\left[\mathrm{k} \otimes \mathrm{I}_{\mathrm{M}}\right]\right)^{\prime} \sum_{\mathrm{u}}^{-1}\left(\sum_{\mathrm{t}}\left(\mathrm{r}_{\mathrm{t}}-\mu-\mathrm{GR}_{\mathrm{t}-1}^{*}\right)\right) \\
\frac{\partial \log \mathrm{L}}{\partial \mu} & =\left(\mathrm{X} \otimes \mathrm{I}_{\mathrm{M}}\right)\left(\mathrm{I}_{\mathrm{Z}} \otimes \sum_{\mu}^{-1}\right)\left(\mathrm{r}-\mu^{*}-\left(\mathrm{X}^{\prime} \otimes \mathrm{I}_{\mathrm{M}}\right) \alpha\right) \\
& =\left(\mathrm{X} \otimes \sum_{\mathrm{u}}^{-1}\right)\left(\mathrm{r}-\mu^{*}\right)-\left(\mathrm{XX}^{\prime} \otimes \sum_{\mathrm{u}}^{-1}\right) \alpha
\end{aligned}
$$

where $\mathrm{k}$ is a s $\times 1$ vector of 1 's. The following MLE will result from equating the system of derivatives to zero:

$\hat{\mu}=\frac{1}{\mathrm{z}}\left(\mathrm{I}_{\mathrm{M}}-\sum_{\mathrm{i}} \widehat{\mathrm{G}}_{\mathrm{i}}\right)^{\prime} \sum_{\mathrm{t}}\left(\mathrm{r}_{\mathrm{i}}-\sum_{\mathrm{i}} \widehat{\mathrm{G}}_{\mathrm{i}} \mathrm{r}_{\mathrm{t}-\mathrm{i}}\right)$

$\widehat{\alpha}=\left(\left(\widehat{X} \widehat{X}^{\prime}\right)^{-1} \widehat{\mathrm{X}} \oplus \mathrm{I}_{\mathrm{M}}\right)\left(\mathrm{r}-\hat{\mu}^{*}\right)$

$\widehat{\Sigma}_{\mathrm{u}}=\frac{1}{\mathrm{Z}}\left(\widehat{\mathrm{R}}^{*}-\widehat{\mathrm{G}} \widehat{\mathrm{X}}\right)\left(\widehat{\mathrm{R}}^{*}-\widehat{\mathrm{G}} \widehat{\mathrm{X}}\right)^{\prime}$

Diagnostic Tests: Diagnostic tests are meant to test the adequacy of the model. After fitting VAR (p) model it is important to ensure that the fitted residuals satisfy the assumptions of the model. Edgerton and Shukur (1999) introduced the test called Portmanteau to test the nonexistence of serial correlation. Null hypothesis 
$\mathrm{H}_{0}$ : the residual is not serially correlated is tested against the alternative $\mathrm{H}_{1}$ : the residual is serially correlated. The test statistic is given as:

$\mathrm{Q}_{\mathrm{h}}=\mathrm{T}^{2} \sum_{\mathrm{i}=1}^{\mathrm{h}} \frac{1}{\mathrm{~T}-\mathrm{i}} \operatorname{tr}\left(\widehat{\mathrm{C}}_{\mathrm{i}}^{\prime} \hat{\mathrm{C}}_{0}^{-1} \widehat{\mathrm{C}}_{\mathrm{j}}^{\prime} \hat{\mathrm{C}}_{0}^{-1}\right)$

where $\hat{\mathrm{C}}_{\mathrm{i}}=\frac{1}{\mathrm{~T}} \sum_{\mathrm{t}=\mathrm{i}+1}^{\mathrm{T}} \hat{\mathrm{u}}_{\mathrm{t}} \hat{\mathrm{u}}_{\mathrm{t}-\mathrm{i}}$. The test statistic $\mathrm{Q}_{\mathrm{h}}$ is asymptotically distributed as a $\chi^{2}\left(\mathrm{~N}^{2} \mathrm{~h}-\mathrm{n}\right)$ where $\mathrm{n}$ denotes deterministic term of a VAR (p) model. Lütkepohl (2007) introduced ma ultivariate Jarque-Bera (JB) test which was firstly introduced by Jarque and Bera (1980). According to Pfaff (2008), "the test can be computed using the residuals standardized by a Choleski decomposition of the variance-covariance matrix of a VAR (p) model". It is also based on the third and fourth $\left(\mathrm{E}\left(\mathrm{y}^{3}=0\right)\right.$ and $\left.\mathrm{E}\left(\mathrm{y}^{4}=3\right)\right)$ moments of a Gaussian distribution. The following are the hypothesis tested for the above test:

$\mathbf{H}_{0}$ : The residual is symmetrically distributed.

H1: The residual is not symmetrically distributed.

The JB test statistic in a multivariate setting is described as follows:

$\mathrm{JB}_{\mathrm{mv}}=\tau_{\mathrm{k}}+\tau_{\mathrm{s}}$

where $\tau_{\mathrm{k}}$ and $\tau_{\mathrm{s}}$ are computed as

$\tau_{\mathrm{k}}=\frac{\mathrm{T}\left(\mathrm{b}_{1}-3_{\mathrm{N}}\right)^{\prime}\left(\mathrm{b}_{1}-3_{\mathrm{N}}\right)}{24}$

$\tau_{\mathrm{s}}=\frac{\mathrm{Tb}_{0}^{\prime} \mathrm{b}_{0}}{6}$

where $b_{0}$ and $b_{1}$ are $3^{\text {rd }}$ and $4^{\text {th }}$ non-central moment vector of the standardized residuals $\hat{\mu}_{t}^{s}=\widehat{P}-\left(\hat{\mu}_{t}-\overline{\hat{\mu}}_{t}\right)$ and $\widehat{\mathrm{P}}$ denotes a lower triangular matrix. It comprises of diagonal positive values such that $\widehat{\mathrm{PP}}^{\prime}=$ $\widehat{\Sigma}_{\mathrm{u}}$ representing the Choleski decomposition of the residual covariance matrix. Breusch (1978) introduced Multivariate ARCH-LM test and it is used to test for heteroskedasticity in the fitted residuals. The test is based on the following equation:

$\hat{u}_{t}=d+G_{1} y_{t}+\cdots+G_{p} y_{t-p}+\cdots+E \hat{u}_{t-1}+\cdots+E_{i} \hat{u}_{t-i}+\epsilon_{t}$

where $G_{i}$ and $E_{i}$ are coefficients matrices and $\epsilon_{\mathrm{t}}$ is the error term from the regression model. The null hypothesis tested is $E_{1}=E_{2}=\cdots=E_{i}=0$ (absence of ARCH errors) against the alternative $\mathrm{H}_{1}$ which test that $E_{i} \neq 0$. The ARCH-LM test statistic in a multivariate setting is denoted as:

$\mathrm{LM}_{\mathrm{i}}=\mathrm{T} \widehat{\mathrm{d}}_{\mathrm{i}}^{\prime} \widehat{\Sigma}_{\mathrm{d}}^{-1} \widehat{\mathrm{d}}_{\mathrm{i}}$

where $d_{i}=\left(D_{1} \ldots \ldots D_{i}\right)^{\prime}$ such that $D_{i}=\frac{1}{T} \sum_{t=i+1}^{T} u_{t} u_{t-i}^{\prime}, \widehat{\sum}_{d}$ is the covariance matrix of the residuals.

Forecasting: Amongst others the multivariate time series analysis aims to predict future values based on the past observed values of a time series. After a VAR model is found adequate from the relevant diagnostic tests, it may be used for predicting future values. For a given VAR (p), h-step ahead forecast is computed using the chain-rule of forecasting as:

$\mathrm{y}_{\mathrm{T}+\mathrm{i} \mid \mathrm{T}}=\mathrm{d}+\mathrm{G}_{1} \mathrm{y}_{\mathrm{T}+\mathrm{i}-1}+\cdots+\mathrm{G}_{\mathrm{p}} \mathrm{y}_{\mathrm{T}+\mathrm{i}-\mathrm{p} \mid \mathrm{T}}$

where $y_{T+j \mid T}=t_{T+j}$ for $\mathrm{j} \leq 0$. The h-step prediction errors are expressed as follows:

$\mathrm{y}_{\mathrm{T}+\mathrm{i}}-\mathrm{y}_{\mathrm{T}+\mathrm{i} \mid \mathrm{T}}=\sum_{\mathrm{s}=0}^{\mathrm{i}-1} \Psi_{\mathrm{s}} \mathrm{u}_{\mathrm{t}+\mathrm{i}-\mathrm{s}}$

The matrices $\Psi_{\mathrm{s}}$ are determined by a recursive substitution 
$\Psi_{\mathrm{s}}=\sum_{\mathrm{j}=1}^{\mathrm{p}-1} \Psi_{\mathrm{s}-\mathrm{j}} \mathrm{G}_{\mathrm{j}}$

where $\Psi_{0}=\mathrm{I}_{\mathrm{N}}$ and $\mathrm{G}_{\mathrm{j}}=0$ for $\mathrm{j}>p$. If all the forecast errors have a zero expectation value then the forecasts are unbiased and MSE matrix of $\mathrm{y}_{\mathrm{t}+\mathrm{i} \mid \mathrm{T}}$ is

$\sum(\mathrm{i})=\operatorname{MSE}\left(\mathrm{y}_{\mathrm{T}+\mathrm{i}}-\mathrm{y}_{\mathrm{T}+\mathrm{i} \mid \mathrm{T}}\right)$

$=\sum_{\mathrm{j}=0}^{\mathrm{i}-1} \Psi_{\mathrm{j}} \sum \Psi_{\mathrm{j}}^{\prime}$

The confidence interval of the forecasts was represented as follows:

$\left[\mathrm{y}_{\mathrm{k}, \mathrm{T}+\mathrm{i} \mid \mathrm{T}}-\mathrm{d}_{1-\frac{\gamma}{2}} \sigma_{\mathrm{k}}(i), \mathrm{y}_{\mathrm{k}, \mathrm{T}+\mathrm{i} \mid \mathrm{T}}+\mathrm{d}_{1-\frac{\gamma}{2}} \sigma_{\mathrm{k}}(\mathrm{i})\right]$

where $d_{1-\frac{\gamma}{2}}$ implies the $\left(1-\frac{\gamma}{2}\right)$ relative point of the symmetry and the $\sigma$ (std dev) of the $\mathrm{k}^{\text {th }}$ variable h-step ahead is denoted by $\sigma_{\mathrm{k}}(i)$.

\section{Results and Discussion}

This section presents the results of the procedure carried out for fitting a VAR model. The lag length selection is presented in Table 1 below.

Table 1: Lag Length Selection

\begin{tabular}{lllll}
\hline Fit & Model & AIC & HQ & SC \\
\hline 1 & VAR(1) & -38.653 & -38.362 & -37.937 \\
2 & VAR(2) & -39.083 & -38.550 & -37.770 \\
3 & VAR(3) & -38.922 & -38.147 & -37.012 \\
4 & VAR(4) & -39.749 & -37.732 & -36.243 \\
5 & VAR(5) & -38.751 & -37.492 & -35.645 \\
6 & VAR(6) & -38.828 & -37.326 & -35.128 \\
\hline
\end{tabular}

Table 1 above shows that AIC and HQ selected lag length 2, while SC selected lag length 1 as an optimal length. Therefore, VAR (1) was computed and presented with its parameters in Table 2.

Table 2: Parameter Estimation

\begin{tabular}{|c|c|c|c|c|c|c|}
\hline $\begin{array}{l}\text { BRICS } \\
\text { Exchange rate }\end{array}$ & Parameter & Variable & Estimate & Std. Error & t-value & p-value \\
\hline \multirow[t]{5}{*}{ Brazil } & $\operatorname{AR}(1)_{11}$ & Brazil $_{\mathrm{t}-1}$ & 0.906 & 0.075 & 12.017 & $<2 \mathrm{e}-16^{* * *}$ \\
\hline & $\operatorname{AR}(1)_{12}$ & Chinat-1 & -0.375 & 0.119 & -3.154 & $0.002 * *$ \\
\hline & $\operatorname{AR}(1)_{13}$ & Indiat-1 & -0.154 & 0.082 & -1.873 & 0.064 \\
\hline & $\operatorname{AR}(1)_{14}$ & Russiat-1 & 0.030 & 0.033 & 0.909 & 0.365 \\
\hline & $\operatorname{AR}(1)_{15}$ & SouthAfricat-1 & 0.137 & 0.073 & 1.879 & 0.063 . \\
\hline \multirow[t]{5}{*}{ China } & $\operatorname{AR}(1)_{21}$ & Brazil $_{t-1}$ & 0.009 & 0.013 & 0.740 & 0.461 \\
\hline & $\operatorname{AR}(1)_{22}$ & Chinat-1 & 0.968 & 0.020 & 48.782 & $<2 \mathrm{e}-16^{* * *}$ \\
\hline & $\operatorname{AR}(1)_{23}$ & Indiat-1 & -0.004 & 0.014 & -0.306 & 0.760 \\
\hline & $\operatorname{AR}(1)_{24}$ & Russiat-1 & 0.001 & 0.005 & 0.213 & 0.832 \\
\hline & $\operatorname{AR}(1)_{25}$ & SouthAfricat-1 & -0.002 & 0.012 & -0.188 & 0.851 \\
\hline \multirow[t]{5}{*}{ India } & $\operatorname{AR}(1)_{31}$ & Brazil $_{\mathrm{t}-1}$ & -0.020 & 0.039 & -0.524 & 0.601 \\
\hline & $\operatorname{AR}(1)_{32}$ & Chinat-1 & -0.214 & 0.061 & -3.504 & $0.001 * * *$ \\
\hline & $\operatorname{AR}(1)_{33}$ & Indiat-1 & 0.843 & 0.042 & 19.942 & $<2 \mathrm{e}-16^{* * *}$ \\
\hline & $\operatorname{AR}(1)_{34}$ & Russiat-1 & -0.002 & 0.017 & -0.114 & 0.909 \\
\hline & $\operatorname{AR}(1) 35$ & SouthAfricat-1 & 0.098 & 0.037 & 2.618 & $0.010 *$ \\
\hline \multirow[t]{2}{*}{ Russia } & $\operatorname{AR}(1)_{41}$ & Brazil $_{t-1}$ & 0.052 & 0.092 & 0.565 & 0.573 \\
\hline & $\operatorname{AR}(1)_{42}$ & Chinat-1 & -0.364 & 0.145 & -2.517 & $0.013 *$ \\
\hline
\end{tabular}




\begin{tabular}{lllllll}
\hline $\begin{array}{l}\text { BRICS } \\
\text { Exchange rate }\end{array}$ & Parameter & Variable & Estimate & Std. Error & t-value & p-value \\
\hline \multirow{6}{*}{ South Africa } & & & & & & \\
& $\mathrm{AR}(1)_{43}$ & Indiat-1 & -0.162 & 0.100 & -1.620 & 0.108 \\
& $\mathrm{AR}(1)_{44}$ & Russiat-1 & 0.923 & 0.040 & 23.123 & $<2 \mathrm{e}-16^{* * *}$ \\
& $\mathrm{AR}(1)_{55}$ & SouthAfricat-1 & 0.127 & 0.089 & 1.426 & 0.157 \\
& $\mathrm{AR}(1)_{51}$ & Brazilt -1 & 0.146 & 0.076 & 1.916 & 0.058 \\
& $\mathrm{AR}(1)_{52}$ & Chinat-1 & -0.297 & 0.120 & -2.469 & $0.015^{*}$ \\
& $\mathrm{AR}(1)_{53}$ & Indiat-1 & -0.117 & 0.083 & -1.400 & 0.164 \\
& $\mathrm{AR}(1)_{54}$ & Russiat-1 & -0.035 & 0.033 & -1.047 & 0.298 \\
& $\mathrm{AR}(1)_{55}$ & SouthAfricat-1 & 0.930 & 0.074 & 12.604 & $<2 \mathrm{e}-16^{* * *}$ \\
\hline
\end{tabular}

Note: '***', '**', '*' and ' ${ }^{\prime \prime}$ indicate significant codes at $0.001,0.01,0.05$ and 0.1 respectively

Table 2 presents the parameter estimates of the VAR (1) model. All the estimated parameters with the probability values less the 0.1 are considered significant and are flagged with an asterisk. From the above Table 1, the following are the significant autoregressive matrix coefficients: $\operatorname{AR}(1)_{11}, \operatorname{AR}(1)_{12}, \operatorname{AR}(1)_{13}$, $\operatorname{AR}(1)_{15}, \operatorname{AR}(1)_{22}, \operatorname{AR}(1)_{32}, \operatorname{AR}(1)_{33}, \operatorname{AR}(1)_{35}, \operatorname{AR}(1)_{42}, \operatorname{AR}(1)_{44}, \operatorname{AR}(1)_{51}, \operatorname{AR}(1)_{52}$, and $\operatorname{AR}(1)_{55}$ implying that there exists a linear dependency between Brazil and its own lagged values, Brazil and lagged values of China, Brazil and lagged values of India, Brazil and lagged values of South Africa, China and its own lagged values, India and lagged values of China, India and its own lagged values, India and lagged values of South Africa, Russia and past values of China, Russia and its own lagged values, South Africa and lagged values of Brazil, South Africa and lagged values of China and lastly South Africa and its own lagged values. All the linear dependencies take one direction. The study by Mohanasundaram and Karthikeyan (2015) revealed similar results of the VAR model. The equations of the VAR (1) model for every variable which possesses the significant parameters are written as follows:

$$
\begin{aligned}
& \text { Brazil }=0.906( \pm 0.075) \text { Brazil }_{1, \mathrm{t}-1}-0.375( \pm 0.119) \text { China }_{2, \mathrm{t}-1}-\quad 0.154( \pm 0.082) \text { India }_{4, \mathrm{t}-1}+ \\
& 0.137( \pm 0.073) \text { SouthAfrica }{ }_{5, \mathrm{t}-1}+\mu_{1, \mathrm{t}} \\
& \text { China }=0.968( \pm 0.020) \text { China }_{2, \mathrm{t}-1}+\mu_{2, \mathrm{t}} \\
& \text { India }=-0.214( \pm 0.061) \text { China }_{2, \mathrm{t}-1}+0.843( \pm 0.042) \text { India }_{3, \mathrm{t}-1}+\quad 0.098( \pm 0.037) \text { SouthAfrica }{ }_{5, \mathrm{t}-1}+ \\
& \begin{array}{l}
\mu_{3, \mathrm{t}} \\
\text { Russia }=-0.364( \pm 0.145) \text { China }_{2, \mathrm{t}-1}+0.923( \pm 0.040) \text { Russia }_{4, \mathrm{t}-1}+\mu_{4, \mathrm{t}}
\end{array} \\
& \text { SouthAfrica }=0.146( \pm 0.076) \text { Brazil }_{1, \mathrm{t}-1}-0.297( \pm 0.120) \text { China }_{2, \mathrm{t}-1}+ \\
& 0.930( \pm 0.074) \text { SouthAfrica }{ }_{5, \mathrm{t}-1}+\mu_{1, \mathrm{t}}
\end{aligned}
$$

Table 3 below presents the covariance matrix of the BRICS exchange rates.

Table 3: Covariance Matrix

\begin{tabular}{llllll}
\hline Variable & BRAZIL & CHINA & INDIA & RUSSIA & SOUTH AFRICA \\
\hline BRAZIL & $1.393 \mathrm{e}-03$ & $5.877 \mathrm{e}-05$ & 0.0004356 & $6.990 \mathrm{e}-04$ & $9.318 \mathrm{e}-04$ \\
CHINA & $5.877 \mathrm{e}-05$ & $3.882 \mathrm{e}-05$ & 0.0000138 & $7.618 \mathrm{e}-05$ & $4.497 \mathrm{e}-05$ \\
INDIA & $4.356 \mathrm{e}-04$ & $1.380 \mathrm{e}-05$ & 0.0003683 & $2.545 \mathrm{e}-04$ & $4.135 \mathrm{e}-04$ \\
RUSSIA & $6.990 \mathrm{e}-04$ & $7.618 \mathrm{e}-05$ & 0.0002545 & $2.067 \mathrm{e}-03$ & $5.456 \mathrm{e}-04$ \\
SOUTH AFRICA & $9.318 \mathrm{e}-04$ & $4.497 \mathrm{e}-05$ & 0.0004135 & $5.456 \mathrm{e}-04$ & $1.431 \mathrm{e}-03$ \\
\hline
\end{tabular}

The results presented as equations 40 to 44 illustrate that there is a presence of concurrent relationship amongst all the BRICS exchange rates. Table 4 presents the model diagnostic tests of the VAR (1).

Table 4: Diagnostic Tests

\begin{tabular}{llll}
\hline Test & Statistic & DF & p-value \\
\hline Portmanteau Test & 243.75 & 125 & $<0.001^{* * *}$ \\
JB-Test & 381.00 & 10 & $<0.001^{* * *}$ \\
Skewness & 52.783 & 5 & $<0.001^{* * *}$ \\
Kurtosis & 328.220 & 5 & $<0.001^{* * *}$ \\
ARCH & 1468.100 & 1350 & $0.0131^{* *}$ \\
\hline
\end{tabular}

Note: ${ }^{(* * *)},{ }^{* * *},{ }^{\prime * \prime}$ and ' $\cdot$ ' indicate significant codes at $0.001,0.01,0.05$ and 0.1 respectively 
Table 4 above gives the summary of the diagnostic tests results for the fitted VAR (1) model. All the probability values including the ARCH p-value are significant at 5\%. This implies that serial correlation was observed from the residuals of the model fitted, there is the presence of ARCH errors and is not symmetrical. The model does not satisfy all the diagnostic tests and cannot be further utilized to predict the following BRICS exchange rates.

\section{Conclusion}

The paper modelled the BRICS exchange rates using the VAR model. The paper used monthly time series data ranging from January 2008 to January 2018. The estimated model and their parameters were presented. All the parameter estimates with the p-values less the 0.1 were considered significant. The model does not satisfy all the diagnostic tests and cannot be used to predict future values of the BRICS exchange rates. The study by Mohanasundaram and Karthikeyan (2015) and Ijumba (2013) revealed similar results of the VAR model. The paper recommends that a similar study could be undertaken to compare the univariate and the multivariate settings. The paper also recommends that a similar study could be reproduced using a highfrequency data (daily or weekly) using the same methodology. The study recommends that BRICS countries should develop policies that allow for the very slow increase of the exchange rates to encourage trade amongst the BRICS countries. The weak exchange rate makes currency more attractive and volatile exchange rates negatively affect trade and reduce investor confidence.

\section{References}

Adenomon, M., Ojehomon, V. T. \& Oyejola, B. (2013). Modelling The Dynamic Relationship Between Rainfall and Temperature Time Series Data In Niger State, Nigeria.

Athanasopoulos, G., de Carvalho guillén, O. T., Issler, J. V. \& Vahid, F. (2011). Model selection, estimation and forecasting in VAR models with short-run and long-run restrictions. Journal of Econometrics, 164, 116-129.

Backus, D. (1986). The Canadian--US Exchange Rate: Evidence from a Vector Autoregression. The Review of Economics and Statistics, 628-637.

Bagliano, F. C. \& Favero, C. A. (1998). Measuring monetary policy with VAR models: An evaluation. European Economic Review, 42, 1069-1112.

Başçi, E. S. \& Karaca, S. S. (2012). The determinants of stock market index: VAR approach to the Turkish stock market. International Journal of Economics and Financial Issues, 3, 163-171.

Bessler, D. A. (1984). Relative prices and money: a vector autoregression on Brazilian data. American Journal of Agricultural Economics, 66, 25-30.

Breusch, T. S. (1978). Testing for autocorrelation in dynamic linear models. Australian Economic Papers, 17, 334-355.

Chamalwa, H. A. \& Bakari, H. R. (2016). A Vector Autoregressive (VAR) Cointegration and Vector Error Correction Model (VECM) Approach for Financial Deepening Indicators AND Economic Growth in Nigeria. American Journal of Mathematical Analysis, 4, 1-6.

Dickey, D. A. \& Fuller, W. A. (1979). Distribution of the estimators for autoregressive time series with a unit root. Journal of the American statistical association, 74, 427-431.

Edgerton, D. \& Shukur, G. (1999). Testing autocorrelation in a system perspective testing autocorrelation. Econometric Reviews, 18, 343-386.

Eklund, B. (2007). Forecasting the Icelandic business cycle using vector autoregressive models.

Enders, W. \& Sandler, T. (1993). The effectiveness of antiterrorism policies: A vector-autoregressionintervention analysis. American Political Science Review, 87, 829-844.

Enisan, A. A. \& Olufisayo, A. O. (2009). Stock market development and economic growth: Evidence from seven sub-Sahara African countries. Journal of economics and business, 61, 162-171.

Estenson, P. S. (1992). The Keynesian theory of the price level: an econometric evaluation using a vector autoregression model. Journal of Post Keynesian Economics, 14, 547-560.

Freeman, J. R., Williams, J. T. \& Lin, T. M. (1989). Vector autoregression and the study of politics. American Journal of Political Science, 842-877.

Hall, A. (1989). Testing for a unit root in the presence of moving average errors. Biometrika, 76, 49-56.

Ijumba, C. (2013). Multivariate Analysis of the BRICS Financial Markets. University of KwaZulu-Natal, Durban. 


\section{Journal of Economics and Behavioral Studies (ISSN: 2220-6140)}

Vol. 10, No. 5, pp. 220-229, October 2018

Jarque, C. M. \& Bera, A. K. (1980). Efficient tests for normality, homoscedasticity and serial independence of regression residuals. Economics letters, 6, 255-259.

Lama, A., Jha, G., Gurung, B., Paul, R. K. \& Sinha, K. (2016). VAR-MGARCH Models for Volatility Modelling of Pulses Prices: An Application.

Liitkepohl, H. (1991). Introduction to multiple time series analysis. Berlin et al.

$\mathrm{Lu}, \mathrm{M}$. (2001). Vector autoregression (VAR) - an approach to dynamic analysis of geographic processes. Geografiska Annaler: Series B, Human Geography, 83, 67-78.

LüTkepohl, H. (2007). New introduction to multiple time series analysis.

Mcmillin, W. D. (1991). The velocity of M1 in the 1980s: evidence from a multivariate time series model. Southern Economic Journal, 634-648.

Mohanasundaram, T. \& Karthikeyan, P. (2015). Cointegration and stock market interdependence: Evidence from South Africa, India and the USA. South African Journal of Economic and Management Sciences, 18, 475-485.

Ono, S. (2011). Oil price shocks and stock markets in BRICs. The European Journal of Comparative Economics, 8, 29-45.

Pfaff, B. (2008). VAR, SVAR and SVEC models: Implementation within R package vars. Journal of Statistical Software, 27, 1-32.

Phillips, P. C. \& Perron, P. (1988). Testing for a unit root in time series regression. Biometrika, 75, 335-346.

Sims, C. A. (1980). Macroeconomics and reality. Econometrica: Journal of the Econometric Society, 1-48.

Tsay, R. S. (2005). Analysis of financial time series, John Wiley \& Sons.

Wang, J. \& Zivot, E. (2006). Modeling Financial Time Series with S-PLUS.

Zhang, T., Yin, F., Zhou, T., Zhang, X. Y. \& Li, X. S. (2016). Multivariate time series analysis on the dynamic relationship between Class B notifiable diseases and gross domestic product (GDP) in China. Scientific reports, 6, 29. 